
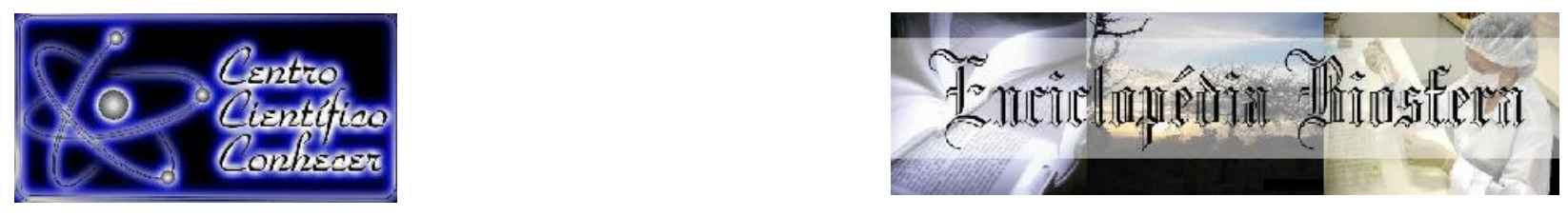

\title{
FITOQUÍMICOS E ATIVIDADE ANTIOXIDANTE DAS ESPÉCIES LAFOENSIA PACARI E CAL YCOPHYLLUM SPRUCEANUM
}

Arielly Polliana Souza dos Anjos ${ }^{1}$, Atney Karine A. Cantanhede ${ }^{1}$, Katarina Mirna Marinho Tenorio ${ }^{2}$, Rodolfo Castilho Clemente ${ }^{3}$, Guilherme Nobre do Nascimento ${ }^{4}$, Renata Junqueira Pereira ${ }^{5}$

1 Nutricionista pela Universidade Federal do Tocantins

2 Doutoranda em Biotecnologia pela Universidade Federal do Tocantins

3 Mestre em Ciências da Saúde e docente do curso de Nutrição da Universidade

Federal do Tocantins

4 Doutor em Química e docente do curso de Nutrição da Universidade Federal do

Tocantins

5 Doutora em Ciência dos Alimentos e docente do curso de Nutrição da

Universidade Federal do Tocantins. Autora para correspondência. E-mail:

renatajunqueira@uft.edu.br

Recebido em: 22/09/2018 - Aprovado em: 23/11/2018 - Publicado em: 03/12/2018 DOI: 10.18677/EnciBio_2018B97

\begin{abstract}
RESUMO
As espécies Lafoensia pacari, pertencente à família Lythraceae e Calycophyllum spruceanum, à família Rubiaceae, têm sido estudadas quanto às suas propriedades antinflamatória, antipirética, cicatrizante, antidiarreica, antifúngica, antimicrobiana e antioxidante. Neste estudo, além da triagem fitoquímica, também foram avaliados os teores de compostos fenólicos totais, a atividade antioxidante e a toxicidade destas espécies. O teor de fenólicos totais foi determinado pelo método de Folin-Ciocalteu. A atividade antioxidante foi determinada pelo método de captação do radical livre 2,2-difenil-1-picril-hidrazil (DPPH). O teste de toxicidade foi conduzido com Allium cepa e a triagem fitoquímica foi realizada por meio de testes analíticos qualitativos. Os compostos em comum encontrados nos extratos foram os ácidos orgânicos, glicosídeos cardioativos e saponinas. As duas espécies apresentaram toxicidade considerável. No que se refere à atividade antioxidante, o extrato de $L$. pacari mostrou-se semelhante ao padrão ácido ascórbico, ao contrário do extrato $C$. Spruceanum, que não apresentou bom poder antioxidante. Em relação aos teores de fenólicos totais dos extratos, observou-se discordância do que é documentado na literatura.
\end{abstract}

PALAVRAS-CHAVE: antioxidantes, compostos fenólicos, fitoquímicos, toxicidade

\section{PHYCHOCHEMICALS AND ANTIOXIDANT ACTIVITY OF THE SPECIES LAFOENSIA PACARI AND CAL YCOPHYLLUM SPRUCEANUM}

\footnotetext{
ABSTRACT

The species Lafoensia pacari, belonging to the family Lythraceae and Calycophyllum spruceanum, to the family Rubiaceae, have been studied for its anti-inflammatory,
} 
antipyretic, healing, antidiarrheal, antifungal, antimicrobial and antioxidant properties. In this study, in addition to phytochemical screening, total phenolic compounds, antioxidant activity and toxicity were also evaluated. The total phenolic content was determined by the Folin-Ciocalteu method. The antioxidant activity was determined by the method of capturing the free radical 2,2-diphenyl-1-picrylhydrazyl (DPPH). The toxicity test was conducted with Allium cepa, and phytochemical screening was performed using qualitative analytical tests. The common compounds found in the extracts were organic acids, cardioactive glycosides and saponins. Both species showed considerable toxicity. In relation to the antioxidant activity, L. pacari extract showed to be similar to the ascorbic acid standard, unlike the $C$. spruceanum extract, which did not present good antioxidant power. In relation to the total phenolic contents of the extracts, it was observed a disagreement of what is documented in the literature.

KEYWORDS: antioxidants, phenolic compounds, phytochemical compounds, toxicity

\section{INTRODUÇÃO}

O uso de recursos naturais como forma alimentícia ou medicinal tem sido uma importante ferramenta, desde os primórdios da humanidade. $O$ conhecimento sobre plantas medicinais simboliza, muitas vezes, o único recurso terapêutico de muitas comunidades e grupos étnicos, para o tratamento e a cura de enfermidades (RIBEIRO et al., 2017). No entanto, há ainda a necessidade de mais estudos científicos, voltados para o uso destas plantas e sua importância no que tange ao aspecto funcional.

O Brasil é o país com maior diversidade genética vegetal do mundo, contando com mais de 55.000 espécies catalogadas, de um total estimado entre 350.000 e 550.000 , o que representa aproximadamente $22 \%$ do total mundial (PIMENTEL et al., 2015). Tal fato contribui positivamente para o surgimento de novas pesquisas no campo da fitoterapia, visto que o Brasil apresenta em seus biomas a floresta amazônica, o pantanal, a mata atlântica, a caatinga e o cerrado, fontes potenciais de diferentes matérias primas vegetais.

O cerrado destaca-se dentre os biomas brasileiros, pois apresenta uma rica biodiversidade. Com extensão de cerca de 2 milhões de quilômetros quadrados, o Brasil Central, com pequena inclusão na Bolívia, ocupa o lugar de segundo maior bioma, sendo superado apenas pela floresta amazônica. Há uma impressão errônea de que o Cerrado é um bioma biologicamente pobre. Ao contrário, esta é uma das regiões de maior biodiversidade do planeta e cobre $25 \%$ do território nacional. Estimativas apontam mais de 6.000 espécies de árvores, além de grande variedade de espécies da fauna (PIMENTEL et al., 2015).

A floresta Amazônica é a maior floresta tropical do mundo, mas ainda não existe consenso científico a respeito de seus limites físicos. De acordo com a OTCA (Organização para o Tratado de Cooperação Amazônica), a Amazônia possui aproximadamente 7 , milhões de $\mathrm{km}^{2}$, sendo que aproximadamente $68 \%$ do território total da floresta amazônica fazem parte do Brasil (PIMENTEL et al., 2015). A riqueza da flora fanerogâmica amazônica tem sido estimada em aproximadamente 21.000 espécies. Comparada com outras florestas úmidas neotropicais, a Floresta Amazônica apresenta maior número de espécies com distribuição ampla.

A Lafoensia pacari é uma planta de porte arbóreo, pertencente à família Lythraceae, popularmente conhecida como "dedaleiro", "louro-da-serra", 
"mangava-brava" ou "dedal" (GALDINO et al., 2015). É uma espécie nativa do Cerrado amplamente utilizada na medicina popular como um agente antiinflamatório, antipirético, cicatrizante, antidiarreico, bem como no tratamento de gastrite e câncer. Estudos realizados com os extratos obtidos das folhas e casca de $L$. pacari demonstraram atividades antimicrobianas, antinociceptiva, antidepressora, antidispéptica, antifúngica, sequestradora de radicais livres e antiinflamatória (SOLON et al., 2000; GALDINO et al., 2015).

A Calycophyllum spruceanum, espécie conhecida popularmente como "mulateiro", "pau-mulato", "mulateiro da várzea", "pau marfim" e "capirona", pertence à família Rubiaceae, (ALMEIDA, 2004; ARAÚJO et al., 2007). Seu local de ocorrência é a Região Amazônica (Brasil, Colômbia, Equador, Peru e Bolívia) na mata de várzea periodicamente inundada à margem dos rios (ALMEIDA, 2004). Utilizada popularmente em alguns países da América do Sul, no Brasil pelas populações amazônicas, como cicatrizante, antimicrobiano, no tratamento de doenças de estômago, intestino, doenças dermatológicas como inflamação da pele e mucosas, parasitoses, câncer no colo uterino, infecções oculares, diabete, feridas infeccionadas, entre outros (ALMEIDA, 2004). Estudos mostraram que o "mulateiro" contém o ácido acetilênico, que pode ser um antibiótico contra fungos e bactérias (ARAÚJO et al., 2007). Há ainda relatos de estudos indicando atividades, antioxidante, antiparasitária, repelente e inseticida (ALMEIDA, 2004).

Diante do exposto, e dada a escassez de artigos científicos que comprovem a eficácia e os compostos funcionais destas plantas, este trabalho visa contribuir com pesquisa de novas informações acerca das características fitoquímicas que estes vegetais possam apresentar em sua composição.

Assim, realizou-se a caracterização fitoquímica, o teste de atividade antioxidante, a determinação do teor de compostos fenólicos e um teste de toxicidade para as espécies Calycophyllum spruceanum e Lafoensia pacari.

\section{MATERIAL E MÉTODOS}

\section{Obtenção dos extratos}

Para a obtenção dos extratos, foram pesados $30 \mathrm{~g}$ do material vegetal seco e moído ao qual foram adicionados $200 \mathrm{~mL}$ de etanol a $98 \%$, cobrindo totalmente a amostra. Em seguida, procedeu-se a extração por refluxo, por 24 horas. Decorrido esse período, as soluções extrativas foram filtradas e a evaporação do solvente foi realizada em evaporador rotativo, com banho-maria à temperatura de $45^{\circ} \mathrm{C}$. Após a total evaporação do solvente, as embalagens contendo os extratos foram envolvidas em filme plástico e armazenadas, sob refrigeração a $4{ }^{\circ} \mathrm{C}$, ao abrigo de luz.

\section{Triagem fitoquímica (Testes analíticos qualitativos)}

A triagem fitoquímica qualitativa, no Laboratório de Ciências Básicas e da Saúde, da Universidade Federal do Tocantins.A caracterização dos principais grupos de substâncias vegetais de interesse foi realizada por meio de reações que resultaram no desenvolvimento de coloração (mudança de cor) e/ou formação de precipitado característico. Foram realizadas três repetições para cada um dos seguintes testes: ácidos orgânicos, açúcares redutores, polissacarídeos, proteínas e aminoácidos, taninos, catequinas, flavonoides, glicosídeos cardioativos, sesquiterpenlactonas e outras, azulenos, carotenoides, 
esteroides e terpenoides, depsídeos e depsidonas, derivados da cumarina, saponinas espumídicas, alcaloides, purinas e antraquinonas.

\section{Análise da atividade antioxidante}

A avaliação quantitativa da atividade antioxidante foi realizada monitorandose o consumo do radical livre 2,2-difenil-1-picril-hidrazil (DPPH/Sigma Aldrich) pelas amostras, através da medida do decréscimo da absorbância de soluções de diferentes concentrações. As leituras foram realizadas em espectrofotômetro, a $515 \mathrm{~nm}$, tendo como controle positivo o ácido L-ascórbico (VITC)/Vetec.

Inicialmente foram preparados $50 \mathrm{~mL}$ de solução estoque de DPPH em metanol, na concentração de $40 \mathrm{~g} / \mathrm{mL}$, mantida sob refrigeração e protegida da luz. Foram feitas diluições de $35,30,25,20,15,10,5$ e $1 \mathrm{~g} / \mathrm{mL}$ dessa solução estoque. A curva analítica foi construída a partir dos valores da absorbância das soluções, a $515 \mathrm{~nm}$, tendo como "branco" o metanol. As medidas de absorbância foram efetuadas em triplicata.

Soluções dos extratos e do controle positivo em metanol foram diluídas nas concentrações de 250, 200, 150, 100, 50 e $25 \mathrm{~g} / \mathrm{mL}$. As leituras das absorbâncias das misturas reacionais $(0,3 \mathrm{~mL}$ da solução da amostra ou do controle positivo e $2,7 \mathrm{~mL}$ da solução estoque de DPPH na concentração de 40 $\mathrm{g} / \mathrm{mL}$ ) foram realizadas a $515 \mathrm{~nm}$, no $1^{\circ}$ minuto e após 1 hora. A mistura de metanol $(2,7 \mathrm{~mL})$ e da solução metanólica do extrato $(0,3 \mathrm{~mL})$ foi utilizada como "branco", tendo sido feito um tubo "branco" para cada concentração.

A partir da equação da curva analítica de DPPH e dos valores de absorbância no tempo de 1 hora, para cada concentração testada, foram determinados os percentuais de DPPH remanescentes (\%DPPHREM), conforme a Equação:

$$
\% \text { DPPHREM }=[\mathrm{DPPH}] \mathrm{T}=\mathrm{t} /[\mathrm{DPPH}] \mathrm{T}=0 \times 100
$$

Onde [DPPH]T=t corresponde à concentração de DPPH no meio, após a reação com o extrato e [DPPH]T=0 é a concentração inicial de $\mathrm{DPPH}$, ou seja, 40 $\mathrm{mg} / \mathrm{mL}(100 \mathrm{~mol} / \mathrm{mL})$.

A concentração eficiente, quantidade de antioxidante necessária para decrescer a concentração inicial de DPPH em 50\% (CE $\left.E_{50}\right)$, foi determinada a partir de uma curva exponencial de primeira ordem, obtida plotando-se na abscissa as concentrações da amostra $(\mathrm{g} / \mathrm{mL})$ ou do controle positivo e na ordenada, a porcentagem de DPPH remanescente (\% DPPHREM).

Os valores de absorbância em todas as concentrações testadas, no tempo de 1 hora, foram convertidos em porcentagem de atividade antioxidante (AA\%), determinada pela Equação:

$$
\% A A=\{[\text { Abscontrole-(Absamostra-Absbranco })] \times 100\} / \text { Abscontrole }
$$

Onde Abscontrole é a absorbância inicial da solução metanólica de DPPH e Absamostra é a absorbância da mistura reacional (DPPH+amostra).

As análises foram realizadas no Laboratório de Ciências Básicas e da Saúde, da Universidade Federal do Tocantins. 


\section{Determinação dos fenólicos totais}

A determinação do teor de fenólicos totais presentes nas amostras de extrato etanólico foi realizada por meio do método de Folin-Ciocalteau, no Laboratório de Ciências Básicas e da Saúde, da Universidade Federal do Tocantins.

Cem miligramas do extrato foram dissolvidos em metanol, transferidos quantitativamente para um balão volumétrico de $100 \mathrm{~mL}$ e o volume final completado com metanol. Uma alíquota de $7,5 \mathrm{~mL}$ desta solução foi transferida para um balão volumétrico de $50 \mathrm{~mL}$. Esta segunda solução teve seu volume acertado novamente com metanol. Uma alíquota de100 L desta última solução foi agitada manualmente com $500 \mathrm{~L}$ do reagente de Folin-Ciocalteau (Cromoline) e $6 \mathrm{~mL}$ de água destilada, por 1 minuto. Decorrido este tempo, foram adicionados $2 \mathrm{~mL}$ de $\mathrm{Na}_{2} \mathrm{CO}_{3}$ a $15 \%$ à mistura, agitando-se por 30 segundos. Finalmente, a solução teve seu volume acertado para $10 \mathrm{~mL}$ com água destilada.

Após $2 \mathrm{~h}$, a absorbância das amostras foi medida a $750 \mathrm{~nm}$, tendo como "branco" o metanol e todos os reagentes, exceto o extrato. O teor de fenólicos totais (FT) foi determinado por interpolação da absorbância das amostras versus uma curva analítica construída com padrão de Ácido Gálico/Sigma Aldrich, nas concentrações de 10 a $350 \mathrm{~g} / \mathrm{mL}$ e expressos como mg de equivalentes de ácido gálico (EAG) por g de extrato. Todas as análises foram realizadas em triplicata.

\section{Análises citotóxica dos extratos}

Para esta análise foi utilizada técnica recomendada por Meneguetti (2014). O experimento utilizou cebolas (Allium cepa) de tamanhos uniformes e da mesma origem, não germinadas e saudáveis. As cebolas foram colocadas para germinar com a parte inferior submersa em 10 frascos de $50 \mathrm{ml}$, os primeiros 5 frascos contendo extrato aquoso de Calycophyllum spruceanum e o 5 restantes de Lafoensia pacari na concentração de $20 \mathrm{~g} / \mathrm{L}$. A água destilada foi utilizada como controle com 5 repetições também. Após 72 horas, as três raízes maiores de cada bulbo foram medidas com o auxílio de paquímetro digital em $\mathrm{mm}$.

\section{Análises de dados}

Os dados foram tabulados e analisados no programa Microsoft Excel, por meio de análises de regressão e estatísticas descritivas. O delineamento foi inteiramente casualizado, com três repetições.

\section{RESULTADOS E DISCUSSÃO}

No que se refere à atividade antioxidante das espécies vegetais estudadas, observa-se que a atividade antioxidante do extrato de $L$. pacari foi muito semelhante à do controle (ácido ascórbico), para todas as concentrações analisadas. Assim pode-se dizer que o extrato de L. pacari demonstrou boa atividade antioxidante, uma vez que se assemelhou à substância parâmetro de alto poder antioxidante (ácido ascórbico), conforme mostrado na Tabela 1.

TABELA 1. Concentrações finais de DPPH em solução e percentuais de DPPH remanescentes, após a reação com ácido ascórbico e com os extratos de $L$. pacari e C. spruceanum, nas diferentes concentrações testadas.

\begin{tabular}{ccccccc}
\hline \multicolumn{4}{c}{ L. pacari } & \multicolumn{2}{c}{ C. spruceanum } & Ácido Ascórbico \\
\hline Conc. & DPPH & DPPH & DPPH & DPPH & DPPH & DPPH \\
de & Final & Rem. & Final & Rem. & Final & Rem. \\
\hline
\end{tabular}




\begin{tabular}{ccccccc}
\hline $\begin{array}{c}\text { Extrato } \\
(\boldsymbol{\mu g} / \mathbf{m L})\end{array}$ & $(\boldsymbol{\mu g} / \mathbf{m L})$ & $(\mu \mathrm{g} / \mathbf{m L})$ & $(\mu \mathrm{g} / \mathbf{m L})$ & $(\mu \mathrm{g} / \mathbf{m L})$ & $(\mu \mathrm{g} / \mathrm{mL})$ & $(\boldsymbol{\mu g} / \mathbf{m L})$ \\
$\mathbf{2 5}$ & 32,05 & 80,13 & 38,01 & 95,03 & 35,07 & 87,66 \\
$\mathbf{5 0}$ & 27,67 & 69,17 & 36,34 & 90,83 & 29,56 & 73,90 \\
$\mathbf{1 0 0}$ & 19,74 & 49,33 & 34,77 & 86,91 & 18,42 & 46,05 \\
$\mathbf{1 5 0}$ & 10,13 & 25,33 & 33,18 & 82,94 & 13,82 & 34,54 \\
$\mathbf{2 0 0}$ & 5,30 & 13,24 & 31,74 & 79,35 & 1,80 & 4,49 \\
$\mathbf{2 5 0}$ & 2,79 & 6,98 & 29,51 & 73,78 & 1,63 & 4,08 \\
\hline
\end{tabular}

Um estudo com extrato aquoso de entrecascas de L. pacari demonstrou capacidade de redução do complexo fosfomolibdênio, mas quando comparada com o padrão ácido ascórbico, essa atividade mostrou ser relativamente baixa, não alcançando 5,0\% da atividade do padrão (CAMPOS; FRASSON; 2011). Resultados destoantes comparados com os apresentados nesse estudo, uma vez que as porcentagens de atividade antioxidante do extrato $L$. pacari se assemelham às do controle ácido ascórbico (Figura 1).

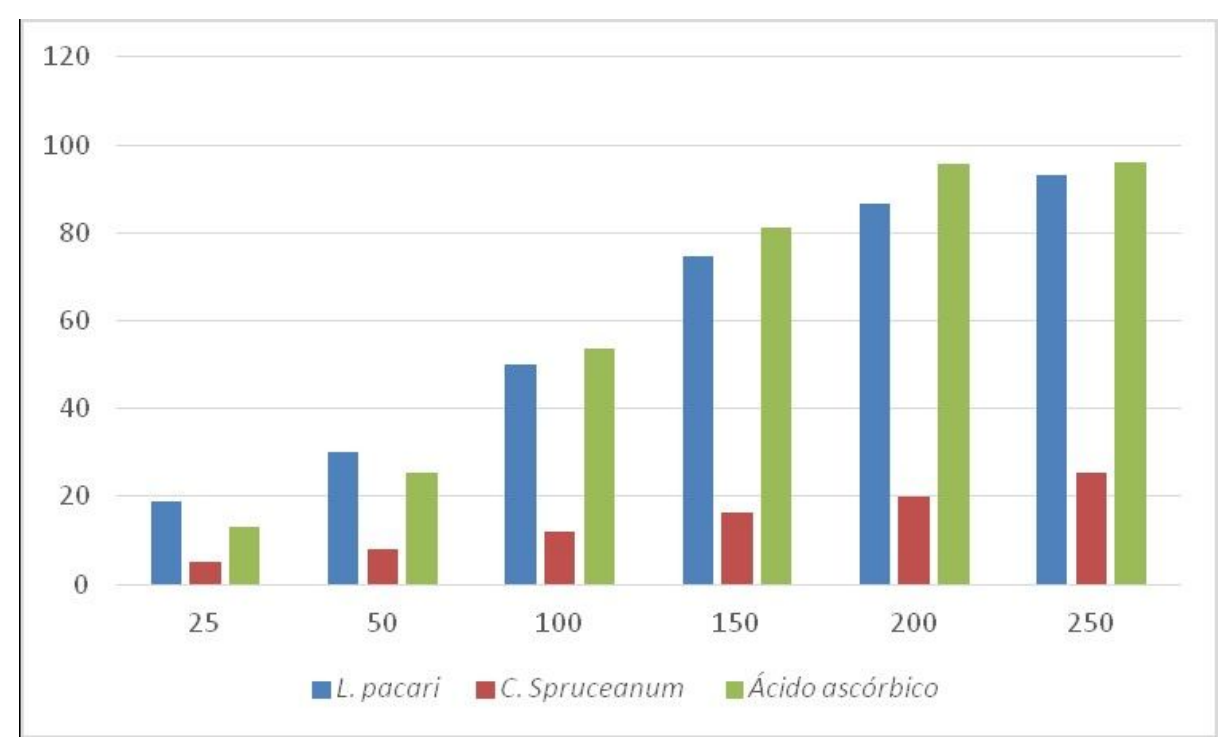

FIGURA 1. Porcentagens de atividade antioxidante nas diferentes concentrações de extratos e controle testadas.

Estudo com a casca da haste e o tronco de $L$. pacari demonstrou que as maiores atividades antioxidantes da casca da haste foram encontradas na fração com éter etílico $(87 \pm 5 \%)$ e nas frações solúveis em butanol (96 $\pm 4 \%)$. Nos testes com as amostras do tronco, o maior potencial antioxidante foi observado em acetato de etila e em acetato de etila: metanol (85:15), o estudo ainda revelou que o principal composto responsável por capturar esses radicais livres nessa espécie foi o ácido elágico, pertencente à classe dos taninos, que foi identificada na triagem fitoquímica do extrato de L. pacari, neste estudo (SOLON et al., 2000) . Outros autores, estudando frações do extrato de L. pacari, observaram que os extratos, hidroalcoólico bruto $(93,20 \%)$, acetato de etila $(93,30 \%)$ e fração metanólica $(93,30 \%)$, foram os que inibiram em maior porcentagem o DPPH, com porcentagens superiores a $90 \%$ nas duas maiores concentrações (FIRMO et al., 2015). Os achados do estudo supracitado se juntam aos do referente estudo e endossam a alta capacidade antioxidante da L. pacari. É importante ressaltar que 
os autores usaram álcoois (etanol/metanol/acetato de etila) diferentes na extração dos extratos, mas chegaram a resultados semelhantes aos da presente análise.

Estudo com a espécie Psychotria fractistipula, pertencente à mesma família do $C$. Spruceanum, analisou a atividade antioxidante do extrato bruto e das frações hexânica, clorofórmica e de acetato de etila, das folhas e do caule, observando que a fração por acetato de etila do caule não demonstrou diferença estatística de atividade antioxidante em relação ao padrão ácido ascórbico (OLIVEIRA, 2016). Já no presente estudo, o extrato de C. Spruceanum, demonstrou baixo potencial antioxidante quando comparado ao ácido ascórbico.

A concentração eficiente (CE50) refere-se à quantidade do extrato necessária para diminuir a concentração inicial de DPPH pela metade. A atividade antioxidante se dá pelo consumo de radicais $\mathrm{DDPH}$ em solução pelo composto antioxidante, de modo que quanto maior o seu consumo na reação, menor será a CE50 do extrato e maior a sua atividade antioxidante. As CE50 dos extratos em relação ao controle são mostradas na Figura 2.

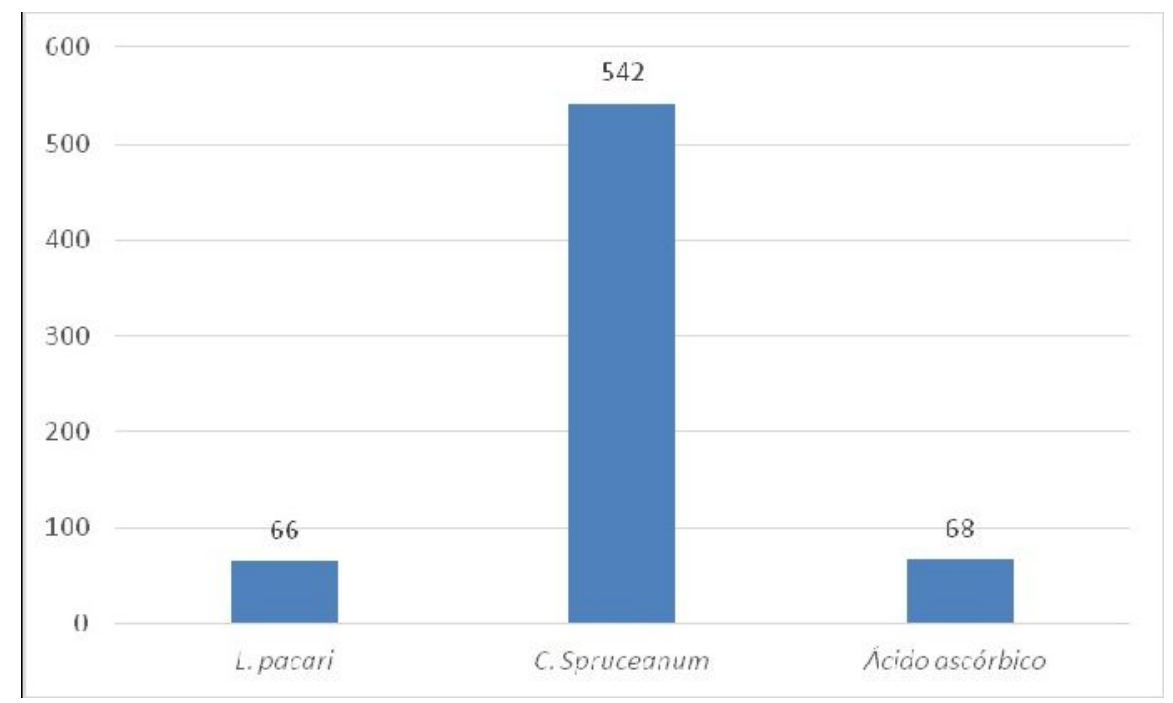

FIGURA 2 - Concentrações de extratos necessárias para decrescer a concentração inicial de DPPH em 50\% (CE50).

As CE50 do extrato de L. pacari foi muito semelhante à do controle ácido ascórbico, ao contrário do verificado para o extrato $C$. Spruceanum. Firmo et al. (2015), analisando as frações do extrato de L. pacari, verificaram que a fração metanólica $(19,69 \mu \mathrm{g} / \mathrm{mL})$ foi a que apresentou um valor menor de CE50 para atividade antioxidante, apresentando, portanto, alto poder antioxidante.

O estudo realizado por Rosa et al. (2010), analisando a espécie Palicourea rigida Kunth, pertencente à família Rubiaceae, realizou testes utilizando o extrato bruto, frações metanólicas, e de acetato de etila, sendo esta última a que apresentou maior atividade antioxidante, de acordo com sua CE50 (192 ppm). Na presente análise o extrato do $C$. Spruceanum apresentou CE50 de $541,9 \mu \mathrm{g} / \mathrm{mL}$, sendo este um valor consideravelmente elevado, quando comparado ao controle ácido ascórbico $(67,7 \mu \mathrm{g} / \mathrm{mL})$, portanto com baixo poder antioxidante.

Com relação à presença de compostos fenólicos, os extratos de Calycophyllum spruceanum e Lafoensia Pacari não apresentaram teores significativos de fenólicos totais, não sendo possível expressar os valores ENCICLOPÉDIA BIOSFERA, Centro Científico Conhecer - Goiânia, v.15 n.28; p.1233 2018 
encontrados dentro dos pontos da curva de ácido gálico construída. Possivelmente os extratos apresentaram teores de fenólicos inferiores a $10 \mathrm{mg}$ de equivalentes de ácido gálico por grama de extrato.

Em relação aos teores de fenólicos demonstrados nas análises do extrato de L. pacari no presente estudo, observa-se discordância com o apresentado no estudo realizado por Firmo et al. (2015), uma vez que em seus resultados todas as frações do extrato bruto apresentaram graus quantificáveis de fenóis, flavonoides e ácidos fenólicos totais, sendo que as frações hidroalcoólica bruta, metanólica e de acetato de etila demonstraram maiores teores de compostos flavonoides, fenóis e ácidos fenólicos. O mesmo constata-se em relação ao encontrado por Campos e Frasson (2011) que realizaram a quantificação de fenóis totais por meio da curva de calibração do ácido tânico, onde as absorbâncias obtidas para o ácido tânico e para o extrato, na concentração de 1 $\mathrm{mg} / \mathrm{mL}$, foram 1,977 e 0,977 , respectivamente.

Outros autores, avaliando as diferenças de extração de compostos vegetais utilizando os solventes etanol e hidroetanol a $70 \%$, constataram que, na maioria das extrações, a utilização do solvente hidroalcoólico favoreceu a extração de substâncias fenólicas (OLIVEIRA et al., 2016). Segundo Rodrigues et al. (2004) a utilização de água pode otimizar a extração de flavonoides e compostos fenólicos, pois aumenta a polaridade da solução extrativa. No presente estudo, a extração foi realizada com etanol a $98 \%$, o que pode ter influenciado na extração dos compostos fenólicos.

Outro trabalho descreve que compostos fenólicos podem sofrer influência de diversos fatores como a natureza do vegetal, do solvente, o tamanho das partículas, o tempo e a temperatura de extração (ANDREO; JORGE, 2006). Segundo Antolovich et al. (2000), não é uma tarefa fácil encontrar um método único de extração que seja adequado para a análise de fenólicos, devido à diversidade das estruturas químicas dessa classe e à variação de sensibilidade dos compostos às condições de extração.

Estudo realizado por Castro et al. (2018) com a espécie Coffea arabica L. pertencente à família Rubiaceae, mesma família do Calycophyllum spruceanum, constatou a presença de fenólicos como flavonoides e ácidos clorogênicos, utilizando curvas analíticas de ácido gálico, clorogênico e quercetina. Rosa et al. (2010) estudando a espécie Palicourea rigida Kunth, pertencente também à Rubiaceae, encontraram a presença de flavonoides em suas análises. Ambos os estudos apresentaram resultados antagônicos aos demonstrados no presente trabalho, porém, Wagini et al. (2014) observaram em seu estudo que pode haver diferença na quantificação de compostos fenólicos totais, devido a superestimação do conteúdo fenólico pelo método de Folin-Ciocalteu, em virtude de que o reagente também pode reagir com compostos não fenólicos, tais como ácidos orgânicos, açúcares e aminoácidos.

As diferenças entre os resultados dos estudos supracitados e os do presente estudo podem ser justificadas pela diferença dos solventes extratores utilizados e sua capacidade extratora, bem como pelas diferenças entre os métodos de determinação de fenólicos utilizados. Sugere-se que futuros estudos realizem a determinação de fenólicos em $L$. pacari e $C$. spruceanum, por outros métodos e por meio de curvas analíticas com outros compostos.

A triagem fitoquimíca do extrato de $L$. pacari revelou a presença de ácidos orgânicos, taninos, catequinas, flavonoides, glicosídeos cardioativos, sesqueterpenlactonas e saponinas. Galdino et al. (2015), após realizarem suas 
análises, encontraram resultados que sugeriram que em seu extrato bruto havia saponinas, taninos, esteroides, triterpenos e traços de flavonoides; na fração clorofórmica encontrou esteroides e triterpenos, enquanto que na fração acetato de etila havia saponinas, esteroides, triterpenos e traços de flavonoides; e nas frações n-butanol e aquosa, apenas saponinas e taninos.

Estudo com o extrato bruto hidroalcoólico do material vegetal da L. pacari, revelou a presença de fenóis, taninos (hidrolisáveis), flavonóis, alcaloides, triterpenos, saponinas, flavanonas, esteroides e terpenoides (FIRMO et al., 2015).

A presença de taninos, flavonoides, saponinas foram verificadas em todas as análises supracitadas, já o grupo dos alcaloides foi encontrado apenas no teste de Firmo et al. (2015), o dos terpenos encontrado nos resultados dos testes de Galdino et al. (2015) e Firmo et al. (2015). Terpenos não foram observados nas análises do presente estudo, porém foram constatadas sesqueterpenlactonas, também pertencentes à classe dos terpenos. As análises da literatura abordada corroboram em sua maioria com os resultados apresentados nos testes deste trabalho, alguns grupos de compostos não foram investigados em todos os trabalhos analisados.

Os fitoquímicos encontrados nos extratos de Calycophyllum spruceanum foram ácidos orgânicos, glicosídeos cardioativos, saponinas e alcaloides. Figueiredo et al. (2009), estudando a espécie Richardia brasiliensis, pertencente à mesma família do $C$. spruceanum, seguiu a mesma metodologia deste estudo e encontraram na parte aérea das raízes: alcaloides, flavonoides, esteroides, triterpenoides, cumarinas e resina, enquanto nas raízes foram detectados esteroides, triterpenoides, cumarinas e resinas. Rodrigues et al. (2014), analisando a espécie Guettarda platypoda, da mesma família citada anteriormente, obtiveram como resultado da triagem a presença de flavonoides, taninos, monoterpenoides, sesquiterpenoides e diterpenoides, triterpenoides, esteroides, saponinas e açúcares redutores. Porém, utilizaram a identificação por cromatografia em camada delgada, utilizando as fases móveis e reveladores específicos descritos na literatura para cada grupo de metabólitos. Para a identificação de saponosídeos foi utilizado o teste de afrogenicidade.

Observa-se que alguns compostos encontrados nas espécies supracitadas, como alcaloides e saponinas, também foram encontrados em $C$. Spruceanum, no presente estudo, sendo que adicionalmente também se determinou a presença de ácidos orgânicos e glicosídeos cardioativos nessa espécie, que não foram observados nas demais.

Após a realização dos testes de citotoxicidade com a espécie de Allium cepa (cebola de cabeça), não foi observado crescimento das raízes das cebolas que foram submersas nos extratos das plantas de $L$. pacari e $C$. spruceanum, verificando-se, portanto, uma atividade tóxica desses extratos, quando comparados ao grupo controle que mostrou desenvolvimento bastante significativo das raízes (Figura 3). 

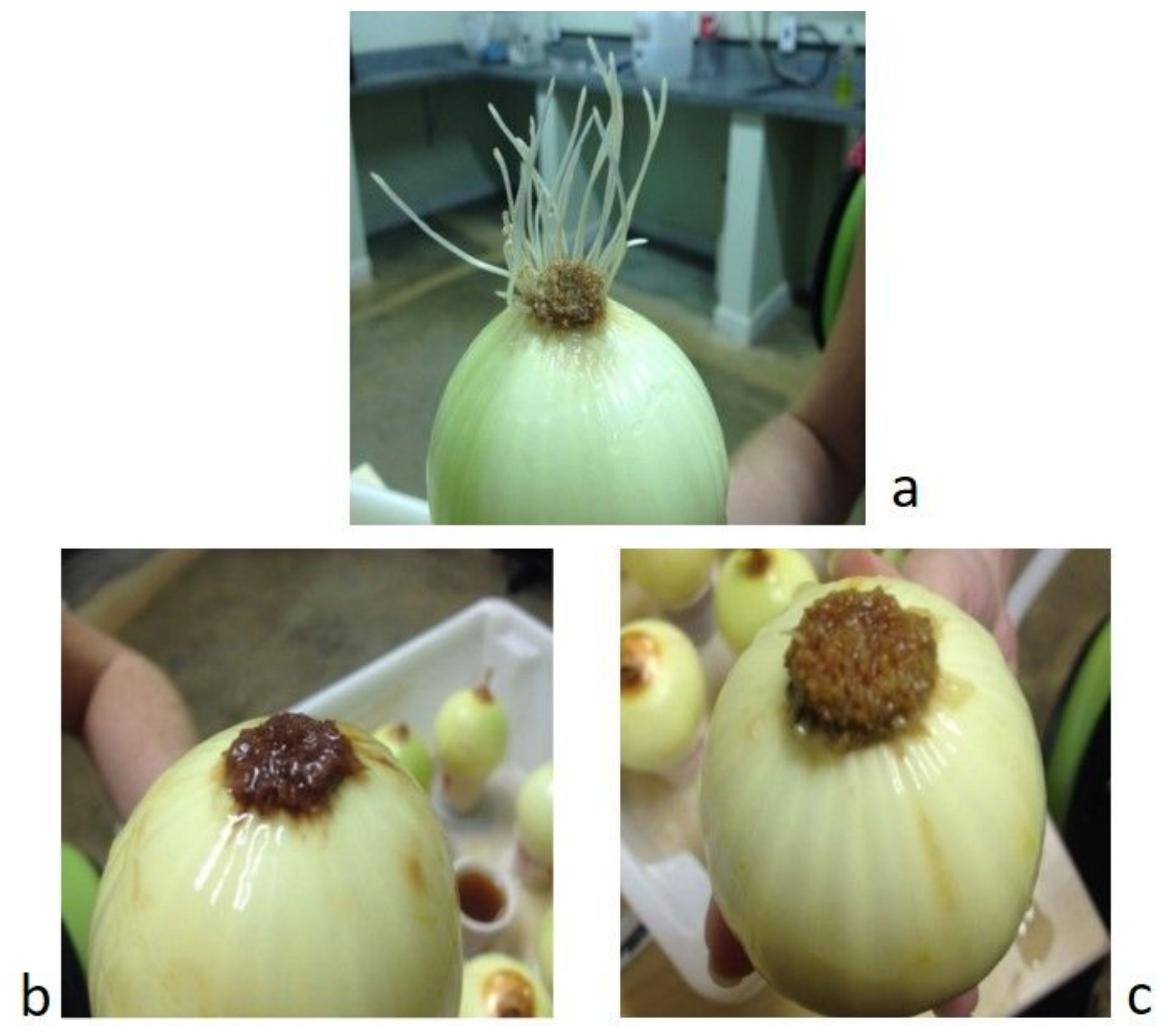

FIGURA 3. Raízes de Allium cepa após a imersão no controle (ácido ascórbico) e nos extratos de L. pacari e C. spruceanum. a (após imersão no controle); b (após imersão no extrato de L. pacarı); c (após imersão no extrato de C. spruceanum).

Estudo que avaliou a citotoxicidade e efeitos apoptogênicos das cascas do caule de L. pacari em células leucêmias e células tumorais, demonstrou alta toxicidade, avaliando o conteúdo de lactato desidrogenase liberado no meio, como um marcador de células mortas (MARCONDES et al., 2014). Esses autores também demonstraram uma queda significativa no índice de proliferação celular, para todas as linhas celulares testadas, após exposição ao extrato. Tais resultados mostram que extratos de Lafoensia pacari, independentemente do modo de extração, exibem efeitos inibidores in vitro significativos contra o crescimento e proliferação celulares.

$\mathrm{Na}$ avaliação da atividade mutagênica e antimutagênica da L. pacari, Lima et al. (2013), por meio do teste de micronúcleo em medula óssea de camundongos, demonstraram que o extrato etanólico da folha de $L$. pacari exibiu uma leve ação citotóxica, apenas na concentração mais elevada e nos tempos de incubação de 24 e $48 \mathrm{~h}$. Já o extrato etanólico da casca do caule de L. pacari exibiu leve efeito citotóxico em todas as doses, no tempo de $24 \mathrm{~h}$. A presença de saponinas na composição da $L$. pacari pode explicar parcialmente a toxicidade constatada nos estudos acima citados, uma vez que Podolak et al. (2010) relataram que as saponinas possuem atividade citotóxica, capacidade de estimular o processo de apoptose, parada do ciclo celular e desintegração do citoesqueleto em células tumorais.

O extrato de $C$. spruceanum impediu a germinação das raízes de cebola da espécie Allium cepa, este achado demonstra uma possível atividade tóxica. Ancia 
e Romão (2015), em seus estudos com a espécie $U$. tomentosa, pertencente à mesma família da $C$. spruceanum, utilizando da mesma metodologia do presente estudo, encontraram crescimento radicular menor que o do controle.

Avaliando a atividade citotóxica por meio de testes realizados com Artemia salina leach, Mesquita et al. (2015) obtiveram resultados que indicaram grande potencial de toxicidade para as espécies Ferdinandusa goudotiana, $F$. hirsuta e $F$. paraenses, espécies da família Rubiaceae. O potencial tóxico observado nos extratos de $C$. spruceanum, mostra-se condizente com os resultados encontrados em testes realizados com espécies da sua mesma família, descritos na literatura.

Os resultados da triagem fitoquímica realizada nesse estudo conflitaram com aqueles apresentados na literatura, porém é importante destacar que a escassez de estudos relacionados às espécies aqui estudadas, dificultou o embasamento científico de parte dos resultados encontrados.

\section{CONCLUSÃO}

Conclui-se que o extrato de Lafoensia pacari demonstrou alta atividade antioxidante, ao contrário do extrato de Calycophyllum spruceanum que não demostrou ser um bom captador de radicais livres. Ambas as espécies não apresentaram teores significativos de fenólicos totais, da forma como foram obtidos seus extratos e exerceram inibição do crescimento celular vegetal.

\section{REFERÊNCIAS}

ALMEIDA, M. DE C. Pau-mulato-da-várzea: Calycophyllum spruceanum (Benth.) Hook. f. ex K. Schum. Informativo Técnico Rede de Sementes da Amazônia, v. 6, 2004. Disponível em: <https://www.inpa.gov.br/sementes/iT/6_Pau-mulato-davarzea.pdf>

ANCIA, J. P.; ROMÃO, N. F. Analise da atividade citotóxica e mutagênica do extrato aquoso das partes aéreas de Uncaria tomentosa em teste de Allium cepa. South American Journal of Basic Education, Technical and Technological, v. 3, n. 2, p. 16-26, $2015 . \quad$ Disponível em: <http://revistas.ufac.br/revista/index.php/SAJEBTT/article/view/195/612>.

ANDREO, D.; JORGE, N. Antioxidantes naturais: técnicas de extração. Boletim do Centro de Pesquisa de Processamento de Alimentos, v. 24, n. 2, 2006. Disponível em: <http://revistas.ufpr.br/alimentos/article/view/7489>. DOI: http://dx.doi.org/10.5380/cep.v24i2.7489

ARAÚJO, V. F. DE; PETRY, A. C.; ECHEVERRIA, R. M.; FERNANDES, E. C.; PASTORE, F. Plantas da Amazônia para Produção Cosmética: uma abordagem química - 60 espécies do extrativismo florestal não-madeireiro da Amazônia. Brasília, $\quad$ p. 244, 2007. Disponível em: $<$ http://www.itto.int/files/itto_project_db_input/2202/Technical/2.2 Plantas da Amazônia para produção cosmética.pdf $>$.

CAMPOS, J. S.; FRASSON, A. P. Avaliação da atividade antioxidante do extrato aquoso de Lafoensia pacari. ST-HIL. em emulsão não-iônica. Revista de Ciências Farmacêuticas Básica e Aplicada, v. 32, n. 3, p. 363-368, 2011. Disponível em: <http://bases.bireme.br/cgibin/wxislind.exe/iah/online/?IsisScript=iah/iah.xis\&src=google\&base=LILACS\&lang 
$=p \&$ nextAction=Ink\&exprSearch $=621570 \&$ indexSearch $=\mid \mathrm{D}>$

CASTRO, A. C. C. M.; ODA, F. B.; ALMEIDA-CINCOTTO, M. G. J.; DAVANÇO, M. G.; CHIARI-ANDRÉO, B. G. et al. Green coffee seed residue: A sustainable source of antioxidant compounds. Food Chemistry, v. 246, p. 48-57, 2018. Disponível

em: https://www.sciencedirect.com/science/article/pii/S0308814617318009. DOI: https://doi.org/10.1016/j.foodchem.2017.10.153

BUSTAMANTE, K. G. L.; FIGUEIREDO, A. D. L.; SOARES, M. L.; PIMENTA, F.C.; BARA, M. T. F. et al. Avaliação da atividade antimicrobiana das partes aéreas (folhas e caules) e raízes de Richardia brasiliensis Gomez (Rubiaceae). Revista de Ciências Farmacêuticas Básica e Aplicada, v. 30, n. 2, p. 65-68, 2009. Disponível em: <https://www.researchgate.net/publication/49599606/download>

FIRMO, W. D. C. A.; MIRANDA, M. V.; COUTINHO, G. S. L.; BARBOZA, J. R.; ALVES, L. P. L. et al. Determinação de compostos fenólicos e avaliação da atividade antioxidante de Lafoensia pacari (LYTHRACEAE). Revista Eletrônica de Farmácia, v. 12, n. 1, p. 1, 2015. Disponível em: https://www.revistas.ufg.br/REF/article/view/24645 https://doi.org/10.5216/ref.v12i1.24645

GALDINO, P. M.; CARVALHO, A. A. V. ; FLORENTINO, I. F. ; MARTINS, J. L. R. ; GAZOLA, A. C. et al. Involvement of monoaminergic systems in the antidepressant-like properties of Lafoensia pacari A. St. Hil. Journal of Ethnopharmacology, v. 170, p. 218-225, 2015. Disponível em:<https://www.ncbi.nlm.nih.gov/pubmed/25980424> DOI: http://doi.org/ 10.1016/j.jep.2015.05.015.

LIMA, D. C. S.; SILVA, C. R.; SAMPAIO, B. L.; PAULA, J. R.; CHEN-CHEN, L. Antigenotoxic, and anticytotoxic activities of an ethanolic extract of Lafoensia pacari (Lythraceae) stem bark in bacteria and mice. Genetics and Molecular Research, v. 12, p. 3887-3896, 2013. Disponível em: <https://www.ncbi.nlm.nih.gov/pubmed/24085450> DOI: http://doi.org/ $10.4238 / 2013$.

MARCONDES, D. B. D. S.; REICHERT, C. L.; ANDRADE, L. F. DE; SANTOS, C. A. DE M.; WEFFORT-SANTOS, A. M. Cytotoxicity and apoptogenic effects of Lafoensia pacari. Journal of Ethnopharmacology, v. 157, p. 243-250, 2014. Disponível em: <https://www.ncbi.nlm.nih.gov/pubmed/25311274> DOI: http://dx.doi.org/10.1016/j.jep.2014.09.018.

MENEGUETTI, D. U. D. O.; LIMA, R. A.; SILVA, J. B.; SILVA, R. P.; PAGOTTO, V. A. F. Análise Citotóxica e Mutagênica do Extrato Aquoso de Maytenus guyanensis Klotzsch Ex Reissek (Celastraceae) Chichuá (Xixuá) Amazônico. Ciência e Natura, v. 36, n. 3, p. 301-309, 2014. Disponível em: http://cascavel.ufsm.br/revistas/ojs-

2.2.2/index.php/cienciaenatura/article/view/13343 DOI: http://dx.doi.org/10.5902/2179460X13343 
MESQUITA, D. W. O.; MESQUITA, A. S. S.; CURSINO, L. M. C.; SOUZA, E. S.; OLIVEIRA, A. C. et al. Atividades biológicas de espécies amazônicas de Rubiaceae. Revista Brasileira de Plantas Medicinais, v. 17, n. 4, p. 604-613, dez. $2015 . \quad$ Disponível em http://www.scielo.br/scielo.php?script=sci_arttext\&pid=S1516-

05722015000400604\&lng=pt\&nrm=iso $\quad$ DOI: http://dx.doi.org/10.1590/1983084X/12_153.

OLIVEIRA, V. B.; ZUCHETTO, M.; OLIVEIRA, C. F.; PAULA, C. S.; DUARTE, A. F. S. et al. Efeito de diferentes técnicas extrativas no rendimento, atividade antioxidante, doseamentos totais e no perfil por CLAE-DAD de Dicksonia sellowiana (presl.). Hook, dicksoniaceae. Revista Brasileira de Plantas Medicinais, v. 18, n. 1 suppl 1, p. 230-239, 2016. Disponível em: http://www.scielo.br/scielo.php?script=sci_arttext\&pid=S1516-

05722016000500230\&lng=pt\&tlng=pt DOI: http://dx.doi.org/10.1590/1983084X/15_106

PARIKH, B.; PATEL, V. H. Quantification of phenolic compounds and antioxidant capacity of an underutilized Indian fruit: Rayan [Manilkara hexandra (Roxb.) Dubard]. Food Science and Human Wellness, v.6, n.1, p. 10-19, 2017. Disponível <https://www.sciencedirect.com/science/article/pii/S2213453016300982> DOI: https://doi.org/10.1016/j.fshw.2016.11.002

PIMENTEL, V.; VIEIRA, V.; MITIDIERI, T.; FRANÇA, F.; PIERONI, J. P. Biodiversidade brasileira como fonte da inovação farmacêutica: uma nova esperança? Revista do BNDES, v.43, p. 41-89, 2015. Disponível em: <http://web.bndes.gov.br/bib/jspui/handle/1408/5602>

PODOLAK, I.; GALANTY, A.; SOBOLEWSKA, D. Saponins as cytotoxic agents: a review. Phytochemistry reviews: proceedings of the Phytochemical Society of Europe, v. 9, n. 3, p. 425-474, 2010. Springer. Disponível em: https://www.ncbi.nlm.nih.gov/pmc/articles/PMC2928447/ https://dx.doi.org/10.1007\%2Fs11101-010-9183-z

RIBEIRO, C. L.; LACERDA, G. E.; PIRES, C. R. F.; NASCIMENTO, G. N. L.; PEREIRA, R. J. Composição centesimal e aspectos físico-químicos dos frutos da bacaba (Oenocarpus distichus Mart.). Revista Cereus, v.9, n.3, 2017. Disponível em: http://ojs.unirg.edu.br/index.php/1/article/view/1412/569

RODRIGUES, G. C. R.; BASTOS, I. V. G. A.; OlIVEIRA, G. G.; PEREIRA JUNIOR, J. A.; PEIXOTO FILHO, R. C. S. et al. Free radical-scavenging activity and cytotoxicity from leaves of Guettarda platypoda. Issues in Biological Sciences and Pharmaceutical Research, v. 2, p. 90-105, 2014. Disponível em: $<$ https://scinapse.io/papers/2186605724> http://dx.doi.org/10.15739/ibspr.003

RODRIGUES, P. O.; GONÇALVES, T. C.; SILVA, W. B. Influência de Diferentes Sistemas de Solventes no Processo de Extração de Calendula officinalis L. 
(Asteraceae). Acta Farmacéutica Bonaerense, v. 23, n. 1, p. 27-31, 2004. Disponível em: < http://hdl.handle.net/10915/6616>

ROSA, E. A.; SILVA, B. C. E; SILVA, F. M.; TANAKA, C. M. A.; PERALTA, K. M. et al. Flavonoides e atividade antioxidante em Palicourea rigida Kunth, Rubiaceae. Revista Brasileira de Farmacognosia, v. 20, n. 4, p. 484-488, 2010. Disponível em: $\quad<h t t p: / / w w w . s c i e l o . b r / s c i e l o . p h p ? s c r i p t=s c i \_a r t t e x t \& p i d=S 0102-$ 695X2010000400004\&lng=pt\&nrm=iso\&tlng=pt> http://dx.doi.org/10.1590/S0102-695X2010000400004

DOI:

SOLON, S.; LOPES, L.; TEIXEIRA DE SOUSA, P.; SCHMEDA-HIRSCHMANN, G. Free radical scavenging activity of Lafoensia pacari. Journal of Ethnopharmacology, v. 72, n. 1-2, p. 173-178, 2000. Disponível em: <https://www.ncbi.nlm.nih.gov/pubmed/10967469> https://doi.org/10.1016/S0378-8741(00)00233-6

WAGINI, N. H.; BELLO, A.; SAFANA, A. I.; ABUBAKAR, S. Phytochemical screening and antibacterial properties of Henna (Lawsonia inermis) roots extracts. Katsina Journal of Natural and Applied Sciences, v. 4, n. 2, p. 151-160, 2015. Disponível em: <https://www.researchgate.net/profile/Nasir_Wagini> 